\title{
Phenolics from Brazilian Propolis
}

G. Boudourova-Krasteva ${ }^{a}$, Vassya Bankova ${ }^{a}$, J. M. Sforcin ${ }^{b}$, N. Nikolova ${ }^{a}$ and

S. Popova

a Institute of Organic Chemistry with Centre of Phytochemistry, Bulgarian Academy

of Sciences, Acad G. Bonchev str. bl. 9, 1113 Sofia, Bulgaria

b Depto. Microbiologia e Imunologia, Instituto de Biociencias,

UNESP 18618-000 Botucatu/SP, BRASIL

Z. Naturforsch. 52c, 676-679 (1997); received April 7/June 9, 1997

Propolis, Phenolics, Flavonoids, Benzopyranes

The main phenolic constituents from Brazilian propolis, originating from Sao Paulo State, were isolated and identified: three flavonoids, a prenylated coumaric acid and two new benzopyranes, $E$ and $Z$ 2,2-dimethyl-6-carboxyethenyl-8-prenyl-2H-benzopyranes.

\section{Introduction}

Propolis, or bee glue, is a complex resinous mixture of plant-derived products collected and used by bees as a general purpose sealer and antibiotic in their hives. It is reported to exhibit a broad spectrum of biological activities, including antibacterial, antiviral, antiinflammatory, cytotoxic etc. (Marcucci, 1995). It is widely used in folk medicine and also as an ingredient in "herbal" preparations sold in pharmacies and "health food" stores in Western countries (Matsuda, 1994). The chemical composition of propolis is very complex (Marcucci, 1995) and is dependent upon the source plant. Bud exudates of different poplar species are the main sources of bee glue in the temperate zone including Europe, Asia and North America (Greenaway et al., 1987; Wollenweber et al., 1987; Bankova et al., 1992). Samples originating from these regions are characterized by similar chemical composition; the most important constituents appeared to be phenolics: flavonoids, aromatic acids and their esters (about $50 \%$ of the weight of propolis) (Marcucci, 1995). In the last few years, tropical propolis has become a subject of increasing interest, concerning its chemistry, origin and biological activity (Aga et al., 1994; Tomas-Barberan et al., 1993; Matsuno, 1994; Bankova et al., 1995). A brief review of the results published on the chemical composition of tropical bee glue

Reprint requests to Dr. Bankova.

Telefax: 003592-700-225. shows a remarkable variability, obviously connected with different plant origin. In this work we report the isolation and characterizatioin of the main phenolic constituents of Brazilian propolis, originating from Sao Paulo State.

\section{Materials and Methods}

\section{Propolis}

Propolis was collected in the Beekeeping Section of the School of Veterinary Medicine and Animal Husbandry of Botucatu, UNESP, in the spring of 1996.

\section{Isolation of phenolics}

Propolis sample $(16.9 \mathrm{~g})$, was extracted twice with $70 \%$ ethanol at room temperature for $24 \mathrm{~h}$. The alcoholic extract was concentrated in vacuo, diluted with water and extracted successively with $n$-hexane (three times) to give $1.56 \mathrm{~g}$ dry extract, and with ethyl acetate (three times) to give $4.46 \mathrm{~g}$ dry extract. The ethyl acetate extract was subjected to column chromatography on silica gel and eluted with chloroform - ethyl acetate gradient to produce several fractions. After repeated column chromatography on silica gel with chloroformmethanol and $n$-hexane - methylethylketone; and preparative TLC on silica gel plates with mobile phases chloroform-acetone, $n$-hexane - acetone and $n$-hexane - methylethylketone; compounds $\mathbf{1}$ - $\mathbf{6}$ were isolated.

Kaempferid (1), $23 \mathrm{mg}$. UV in $\mathrm{MeOH}$ and UV with shift reagents, ${ }^{1} \mathrm{H}$ NMR, ${ }^{13} \mathrm{C}$ NMR and mass 
spectra were identical with literature data for kaempferid (see Results and Discussion).

5,6,7-Trihydroxy-3,4'-dimethoxyflavone

$32 \mathrm{mg}$. UV and ${ }^{1} \mathrm{H}-\mathrm{NMR}$ spectra identical with literature data. ${ }^{13} \mathrm{C}$ NMR spectrum $\left(\mathrm{DMSO}-\mathrm{d}_{6}\right): \delta$ 55.5 (OMe-4); 60.2 (OMe-3); 94.0 (C-8); 103.6 (C10); 114.2 (C-3', C-5'); 123.4 (C-1'); 129.5 (C-2', C6); 131.0 (C-6); 135.9 (C-3); 151.6 (C-9); 151.9 (C5); 157.5 (C-7); 160.7 (C-2); 176.4 (C-4).

Aromadendrine-4'-methyl ether (3), $13.7 \mathrm{mg}$. $\mathrm{UV},{ }^{1} \mathrm{H}$ NMR, ${ }^{13} \mathrm{C}$ NMR spectra identical with literature data.

9-E-2,2-dimethyl-6-carboxyethenyl-8-prenyl-2H1-benzopyrane $(\mathbf{5}, 4.9 \mathrm{mg}$ white solid. UV $(\mathrm{MeOH}): \quad \lambda_{\max }, \quad \mathrm{nm} \quad 231, \quad 269, \quad 317 .{ }^{1} \mathrm{H}-\mathrm{NMR}$ spectrum $\left(\mathrm{CDCl}_{3}\right): \delta 1.44\left(6 \mathrm{H}, \mathrm{s}, \mathrm{CH}_{3}-12\right.$ and $\mathrm{CH}_{3}-$ 13); 1.74 (6H, s, $\mathrm{CH}_{3}-17$ and $\left.\mathrm{CH}_{3}-18\right) ; 3.25(2 \mathrm{H}$, d, $J=7.3 \mathrm{~Hz}, \mathrm{H}-14) ; 5.26(1 \mathrm{H}, \mathrm{m}, \mathrm{H}-15) ; 5.65(1 \mathrm{H}, \mathrm{d}$, $J=10 \mathrm{~Hz}, \mathrm{H}-3) ; 6.30(1 \mathrm{H}, \mathrm{d}, J=16 \mathrm{~Hz}, \mathrm{H}-10) ; 6.33$ $(1 \mathrm{H}, \mathrm{d}, J=10 \mathrm{~Hz}, \mathrm{H}-4) ; 7.04(1 \mathrm{H}, \mathrm{d} J=2.1 \mathrm{~Hz}, \mathrm{H}-7)$; $7.18(1 \mathrm{H}, \mathrm{d}, J=2.1 \mathrm{~Hz}, \mathrm{H}-5) ; 7.67(1 \mathrm{H}, \mathrm{d}, J=16 \mathrm{~Hz}$,
H-9). ${ }^{13} \mathrm{C}$-NMR.-spectrum $\left(\mathrm{CDCl}_{3}\right): \delta 17.9$ and 25.8 (C-17 and 1-18); 28.0 (C-12 and C-13); 77.1 (C-2); 113.7 (C-10); 121.0; 121.9 (C-3); 124.4 126.2; 129.9 (C-4); 131.1; 140.6; 147.2 (C-9); 153.2 (C-8a); $171.4(\mathrm{C}-11)$.

9-Z-2,2-Dimethyl-6-carboxyethenyl-8-prenyl$2 \mathrm{H}$-1-benzopyrane (6), $1.4 \mathrm{mg}$. UV.(MeOH) $\lambda_{\max }$, nm 232, 262, 307. ${ }^{1} \mathrm{H}-\mathrm{NMR}$ spectrum $\left(\mathrm{CDCl}_{3}\right): \delta$ $1.44\left(6 \mathrm{H}, \mathrm{s}, \mathrm{CH}_{3}-12\right.$ and $\left.\mathrm{CH}_{3}-13\right) ; 1.74\left(6 \mathrm{H}, \mathrm{s}, \mathrm{CH}_{3}-\right.$ 17 and $\left.\mathrm{CH}_{3}-18\right) ; 3.25(2 \mathrm{H}, \mathrm{d}, J=7.3 \mathrm{~Hz}, \mathrm{H}-14) ; 5.26$ $(1 \mathrm{H}, \mathrm{m}, \mathrm{H}-15) ; 5.65(1 \mathrm{H}, \mathrm{d}, J=10 \mathrm{~Hz}, \mathrm{H}-3) ; 5.80$ $(1 \mathrm{H}, \mathrm{d}, J=12.8 \mathrm{~Hz}, \mathrm{H}-10) ; 6.33(1 \mathrm{H}, \mathrm{d}, J=10 \mathrm{~Hz}, \mathrm{H}-$ 4); 6.87 (1H, d, J=12.8 Hz, H-9); 3.36 (2H, m, H-5 and $\mathrm{H}-7)$.

\section{Results and Discussion}

From the sample investigated, six individual compounds were isolated.

The first compound isolated was identified as kaempferid (1) (4'-O-methyl kaempferol) by com-<smiles>[R]c1c(O)cc2oc(-c3ccc(OC)cc3)c(O)c(=O)c2c1O</smiles>

1: $R=R^{\prime}=H$

2: $\mathrm{R}=\mathrm{Me} \cdot \mathrm{R}^{\prime}=\mathrm{OH}$

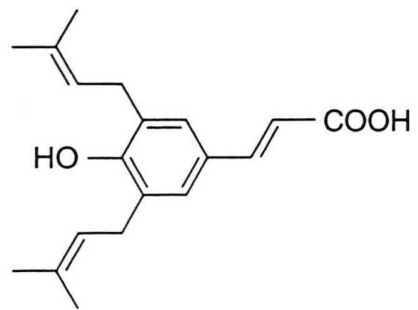

4<smiles>COc1ccc(C2Oc3cc(O)cc(O)c3C(=O)C2O)cc1</smiles>

3

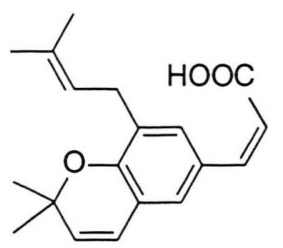


paring its UV, ${ }^{1} \mathrm{H}-\mathrm{NMR}$ and ${ }^{13} \mathrm{C}-\mathrm{NMR}$ spectra with literature data (Mabry et al., 1970, Markham et al., 1982, Popravko et al., 1969). This flavonoid was found earlier in propolis from the European part of Russia and was shown to originate from the bud exudate of birch (Betula spp.) (Popravko, 1976). It was identified recently in Brazilian propolis, too, its source remaining unknown (Bankova et al., 1996).

The second compound isolated was a flavone, according to its UV spectra (with and without shift reagents). Analysis of the ${ }^{1} \mathrm{H}-\mathrm{NMR}$ and ${ }^{13} \mathrm{C}-\mathrm{NMR}$ spectra and NOE experiments allowed us to locate three hydroxyl groups in ring A, a methoxyl group at C-3 and a second methoxyl at C-4' position. Reviewing the literature we found that this flavonoid was identical with 5,6,7-trihydroxy-3,4'-dimethoxyflavone (2) (UV spectra, including spectra with shift-reagents, and $\left.{ }^{1} \mathrm{H}-\mathrm{NMR}\right)$, which was synthesized by Horie et al. (1993). To the best of our knowledge, this is the first isolation of $\mathbf{2}$ from a natural source.

The third compound isolated was a flavonoid, too. According to its UV-spectra it was a flavanone and was identified as aromadendrine-4'methy ether (3), by comparing its UV, ${ }^{1} \mathrm{H}-\mathrm{NMR}$ and ${ }^{13} \mathrm{C}$-NMR spectra with literature data (Bohm, 1982, and literature cited there). This flavanone has previously been rerported from different plant sources, but this is its first isolation from propolis.

The fourth compound isolated was identified as prenylated $p$-coumaric acid (4) (UV, ${ }^{1} \mathrm{H}-\mathrm{NMR}$ ), isolated from Brazilian propolis by Aga et al., 1994.
Upon analysis of its ${ }^{1} \mathrm{H}-\mathrm{NMR}$ spectrum, the fifth compound isolated turned out to be a mixture of two isomeric cinnamic acid derivatives, $E / Z$ ratio $2: 1$. The isomers were separated by TLC and their $\mathrm{UV},{ }^{1} \mathrm{H}-\mathrm{NMR}$ and ${ }^{13} \mathrm{C}$-NMR spectra measured. The structures were determined as $9-E$ and $9-Z$ 2,2-dimethyl-6-carboxyethenyl-8-prenyl-2H-

benzopyran (5) and (6), comparing the spectra with data of similar compounds (3,5-diprenyl-4hydroxycinnamic acid, Aga et al. (1994); 2,2-dimethyl-6-carboxyethenyl-2H-benzopyran, Labbe et al. (1986)). To the best of our knowledge, both 5 and $\mathbf{6}$ are novel compounds.

Identification of new compounds in propolis can give useful hints to its plant sources. Prenylated coumaric acid (4), and benzopyranes similar to 5 and $\mathbf{6}$, originating from prenylated coumaric acids, have been found in different Baccharis species. The genus Baccharis is widespread in South America and is known to produce a leaf exudate, containing phenolic compounds, flavonoid aglycones and terpenes (Wollenweber et al., 1986, 1989). According to the literature data and our own results, some Baccharis spp. are probably among the plant sources of the investigated sample. Obviously, more investigations are needed, including phytochemical investigations on the probable source plants, in order to clear the origin of tropical propolis and especially Brazilian propolis.

\section{Acknowledgements}

Partial support of this work by the National Foundation for Scientific Research (Contract \#X513 ) is gratefully acknowledged. The authors are thankful to Mrs. Manolova for the NMR spectra. 
Aga H., Shibuya T., Sugimoto T., Kurimoto M. and Nakajima Sh. (1994), Isolation and identification of antimicrobial compounds in Brazilian propolis. Biosci. Biotech. Biochem. 58, 945-946.

Bankova V., Dyulgerov A., Popov S., Evstatieva L., Kuleva L., Pureb O. and Zamjanzan Z. (1992), Propolis in Bulgaria and Mongolia: phenolic compounds and plant origin. Apidologie 23, 79-85.

Bankova V., Christov R., Kujumgiev A., Marcucci M. C. and Popov S. (1995), Chemical composition and antibacterial activity of Brazilian propolis. Z. Naturforsch. 50c, $167-172$.

Bankova V., Nikolova N. and Marcucci M. (1996), A new lignan from Brazilian propolis. Z. Naturforsch. 51b, 735-737.

Bohm B. A. (1982), The minor flavonoids. In: The flavonoids: Advances in research. (J. B. Harborne and T. J. Mabry, eds.) Chapman and Hall, London, pp. 313-417.

Greenaway W., Scaysbrook T. and Whatley F. R. S. (1987), The analysis of bud exudate of Populus x euramericana, and propolis, by gas chromatography-mass spectrometry. Proc. R. Soc. Lond. B 232, 249-272.

Horie T., Tominaga H., Yoshida I. and Kawamura Y. (1993), Studies on the selective O-alkylation and dealkylation of flavonoids. XIV. A convinient method for synthesising 5,6,7-trihydroxy-3-methoxyflavones from 6-hydroxy-3,5,7-trimethoxyflavones. Bull. Chem. Soc. Jpn. 66, 877-881.

Labbe C., Rovirosa J., Faini F., Mahu M., San-Martin A. and Castillo, M. (1986), Secondary metabolites from chilean Baccharis species. J. Nat. Prod. 49, 517-518.

Mabry T. J., Markham K. R. and Thomas M. B. (1970), The systematic identification of Flavonoids. Springer, Berlin Heidelberg New York.
Marcucci M. C. (1995), Propolis: chemical composition, biological properties and therapeutic activity. Apidologie 26, 83-99.

Markham K. R., Mohan Chari V. and Mabry T. (1982), Carbon-13 NMR spectroscopy of flavonoids. In: The Flavonoids: Advances in Research (J. B. Harborne, T. J. Mabry, Eds). Chapman and Hall, London New York.

Matsuda, Sh. (1994), Propolis - health care food. Foods \& Food Ingr. J. Jap. 160,. 64-73.

Matsuno, T. (1994), A new clerodane diterpenoid isolated from propolis. Z. Naturforsch. 50c, 93-97.

Popravko S. A., Gurevich A. I. and Kolosov M. N. (1969), [Flavonoid components of propolis]. Chim. Prir. Soed. 5, 476-482 (in Russian).

Popravko S. A. (1976), [Plant sources of propolis]. Pchelovodstvo (7), 38-39 (in Russian).

Tomas-Barberan F. A., Garcia-Viguera C., Vit-Olivier P., Ferreres, F. and Tomas-Lorente, F. (1993), Phytochemical evidence for the botanical origin of tropical propolis from Venezuela. Phytochemistry 34, 191196.

Wollenweber E., Arriaga-Giner F. J., Rumbero A. and Greenaway W. (1989), New phenolics from Baccharis leaf exudate. Z. Naturforsch. 44c, 727-730.

Wollenweber E., Asakawa Y., Schillo D., Lehmann U. and Weigel H. (1987), A novel caffeic acid derivative and other constituents of Populus bud excretion and propolis. Z. Naturforsch. 42c, 1030-1034.

Wollenweber E., Schober J., Dostal P. and Hardetzky D. (1986), Flavonoids and terpenoids from the exudates of some Baccharis species. Z. Naturforsch. 41c, 87-93. 